\title{
Psychometric analysis of the Spanish and Catalan versions of the Diabetes Self-Care Inventory- Revised version questionnaire
}

This article was published in the following Dove Press journal:

Patient Preference and Adherence

2 October 2013

Number of times this article has been viewed

\section{Margarida Jansà' \\ Mercè Vidal' \\ Marga Giménez' \\ Ignacio Conget' \\ Mercedes Galindo 2 \\ Daria Roca' \\ Cristina Colungo ${ }^{3}$ \\ Enric Esmatjes' \\ Manel Salamero ${ }^{4}$}

'Diabetes Unit, Endocrinology and Nutrition, Hospital Clinic, Barcelona, ${ }^{2}$ Endocrinology and Nutrition

Department, Hospital Clinico, Madrid, ${ }^{3}$ Primary Care Centre, Hospital Clinic, Barcelona, ${ }^{4}$ Psychology Department, Hospital Clinic, Barcelona, Spain
Correspondence: Margarida Jansà Diabetes Unit, Endocrinology and Nutrition, Institut Clinic de Malalties Digestives i Metabòliques Hospital Clinic, 170 Villarroel St, 08036 Barcelona, Spain Tel +34932279846

Fax +349345I 6638

Email mjansa@clinic.ub.es
Background: The purpose of this study was to validate the Spanish and Catalan versions of the Diabetes Self-Care Inventory-Revised Version (SCI-R) questionnaire to assess the degree of adherence to self-care among adults with diabetes.

Methods: We validated the Spanish and Catalan translation from, and back translation to, English and cultural adaptation of the SCI-R in type 1 diabetes patients on multiple insulin doses or continuous subcutaneous insulin infusion and in type 2 diabetes patients on oral agents and/or insulin. Internal reliability, structural validity, and external validity (correlation with glycated hemoglobin) were evaluated. Responsiveness to change was assessed in patients 1 year after onset of type 1 diabetes and following a structured education program.

Results: The SCI-R presented good internal reliability Cronbach's $\alpha: 0.75$, test-retest reliability $(r=0.82)$ and structural validity $(r>0.40)$. The external validity was also good; the SCI-R correlated with $\mathrm{HbA1} \mathrm{c}$ in patients with type 1 diabetes on multiple insulin doses $(r=-0.50)$ or continuous subcutaneous insulin infusion $(r=-0.66)$ and in patients with type 2 diabetes on multiple insulin doses $(r=-0.62)$. However, it was not satisfactory in patients on oral agents $(r=-0.20)$ and/or bedtime insulin $(r=-0.35)$. Responsiveness to change was analyzed in 54 patients (age $27.3 \pm 7.4$ years, $26 \%$ men, HbAlc $6.8 \% \pm 1.1 \%$ ); the SCI-R score was $72.3 \%$ $\pm 13.7 \%$ and correlated negatively with glycated hemoglobin $(r=-0.42)$ and 3 scales of the Diabetes Quality of Life questionnaire (lower score indicating better perception): Impact ( $r=$ $-0.37)$, Social Worry $(r=-0.36)$ and Diabetes Worry $(r=-0.38)$, all at $P<0.05$.

Conclusion: The Spanish and Catalan versions of the SCI-R questionnaire show good psychometric properties and both could be considered as useful tools for evaluating self-care behavior in patients with type 1 or type 2 diabetes. However, there are still some subgroups of patients with type 2 diabetes in which the validity of this questionnaire needs further evaluation.

Keywords: diabetes, self-care, questionnaire, adherence, validation, patient education

\section{Introduction}

Diabetes self-management education is a critical element of care for all people with diabetes and is necessary in order to improve patient outcomes. ${ }^{1}$ Diabetes is a chronic condition with highly complex self-managed treatment, ${ }^{2}$ including pharmacologic (pills, insulin administration) and nonpharmacologic (diet, physical exercise) treatment, self-monitoring of blood glucose and ketones, and other activities, such as examination of the feet and frequent attendance for medical follow-up. The American Association of Diabetes Educators states ${ }^{3}$ that there are seven essential self-care behaviors in people with diabetes, ie, healthy eating, being physically active, monitoring of blood sugar, compliance with medication, good problem-solving skills, health coping skills, and risk reduction behaviors. Therefore, it is important to consider adherence to these 
factors in a global and specific way because a patient may be adherent to a specific self-care behavior and not adherent or poorly adherent to another. Problems with adherence to self-care are observed when a patient needs to self-administer treatment.

The number of scientific articles related to treatment adherence in patients with chronic conditions has grown impressively during recent decades. ${ }^{4-10}$ Nevertheless, despite these efforts, lack of adherence remains an unresolved problem. Diabetes is a chronic condition with poor rates of both pharmacologic and nonpharmacologic adherence, and many studies have specifically analyzed pharmacologic adherence. ${ }^{11-16}$ Good adherence to self-care in diabetes ${ }^{17-19}$ is indeed linked to better clinical, economic, and utilization outcomes, while poor adherence is associated with increased morbidity and mortality, higher direct costs associated with hospitalizations for acute complications, and higher indirect costs associated with a reduction in work productivity.

Analysis of adherence is of interest in many disciplines given that even the best treatment loses its efficacy if patients do not follow it correctly. Despite adherence being related to multidimensional factors, there is evidence of its relationship with patient education. Golay et $\mathrm{al}^{20}$ described adherence as an outcome of therapeutic patient education together with the prevention of diabetes complications and quality of life perception. Moreover, patient adherence may change as a result of circumstances, therapeutic interventions, age, type of treatment, and follow-up, so it is necessary to consider adherence as a dynamic process that must be periodically evaluated.

In clinical practice, the health care provider needs well validated methods to assess adherence to self-care, but there are no questionnaires with good psychometric characteristics in Spain. The questionnaire proposed to validate the SelfCare Inventory-Revised Version (SCI-R) was adapted from the original Self-Care Inventory which was developed by La Greca for pediatric patients and updated and validated for adults with type 1 and type 2 diabetes by Weinger et al. ${ }^{21}$ The SCI-R was recently evaluated in the UK in adults with type 2 diabetes using data from the AT.LANTUS study. ${ }^{22}$ One characteristic of the SCI-R is that it does not assume that each patient has the same regimen, and allows for some flexibility in diabetes treatment.

The aim of the review by Eigenmann et $\mathrm{al}^{23}$ was to critically appraise the suitability, validity, reliability, feasibility, and sensitivity to change of the psychometric tools available for measuring the education outcomes, and identified the SCI-R as meeting all these criteria except for no formal test-retest reliability.
Despite the clinical importance of evaluating adherence to self-care in patients with diabetes, there are no well validated questionnaires in Spain. Moreover, in Catalonia (an autonomous community in the north east of Spain) there are two official languages, ie, Spanish and Catalan.

For these reasons, the objective of this study was to determine the psychometric properties, including test-retest reliability, of the Spanish and Catalan versions of the SCI-R questionnaire to assess adherence to self-care behaviors in adult patients with type 1 or type 2 diabetes using different types of pharmacologic treatment.

\section{Materials and methods \\ Characteristics of the survey}

The SCI-R is a 15-question, self-reported measure assessing patient perceptions of their adherence to diabetes self-care recommendations over the previous $1-2$ months: four items address diet, two address glucose monitoring, three address medication administration, one addresses exercise, two address low glucose levels, and three address preventative/ routine aspects of self-care. For patients with type 2 diabetes, three items (checking ketones, adjusting insulin, and wearing Medic Alert) were not scored. Each question was graded on a Likert scale of 1 (never), 2 (rarely), 3 (sometimes), 4 (usually), and 5 (always). The questions cover the self-care behaviors defined by the American Association of Diabetes Educators ${ }^{3}$ and are sound for Spanish patients with diabetes.

The psychometric analyses of the Spanish and Catalan SCI-R versions involved three phases: first, translation, back translation, and cultural adaptation from the English version to Spanish and Catalan versions of the questionnaire; second, internal reliability, structural validity, and external validity; and third, responsiveness to change. Ethical approval of the study protocol and patient consent forms were obtained from the ethical committee of the Hospital Clinic of Barcelona. Participants provided their informed written consent before participation.

\section{Translation, back translation, and cultural adaptation from English version to Spanish and Catalan versions of the questionnaire}

The original English version of the SCI-R was translated into the Spanish and Catalan languages by one endocrinologist, two diabetes nurses, and one psychologist expert in psychometry followed by a group discussion and unification of versions. Both questionnaires were then back translated to English by two independent English translators and compared with the original version. Unified Spanish and 
Catalan versions were made. Ten bilingual Spanish and Catalan patients with type 1 or type 2 diabetes answered the questionnaires to detect and modify any words that were difficult for patients to understand. Thereafter, final versions of Spanish and Catalan questionnaires were made.

\section{Internal reliability, structural validity, and external validity}

The participants were patients aged $>18$ years with type 1 diabetes for a duration of more than 1 year and were receiving treatment with multiple daily injections of insulin or continuous subcutaneous insulin infusion. Type 2 diabetes patients receiving oral agents, bedtime insulin, or multiple insulin doses were recruited from two hospitals and two primary care centers in Barcelona and Madrid and regularly attended medical or educational appointments. According to language preference, the participants answered either the Spanish or Catalan questionnaire (balance approximately $50 \%$ each) to avoid any potential sources of bias.

\section{Internal reliability}

Patients answered the questionnaire selected twice within a maximum of one week. Scores on both questionnaires were analyzed by Cronbach's alpha. Test-retests were correlated. For each item, we calculated the mean and standard deviation, the acceptability ( $\%$ floor, $\%$ ceiling), and the internal consistency reliability (item-total correlation and Cronbach's alpha if item deleted).

\section{Structural validity}

For structural validity, the correlation was obtained for each question with the total score. Principal component analysis with orthogonal rotation (Varimax) was performed.

\section{External validity}

The mean adherence SCI-R scores were correlated with glycated hemoglobin $\left(\mathrm{HbA}_{1 \mathrm{c}}\right)$ values determined during the previous month and were classified depending on diabetes treatment.

\section{Responsiveness to change}

We performed a longitudinal, prospective, single-center study including all patients with newly diagnosed type 1 diabetes referred to the diabetes unit at the hospital clinic of Barcelona during the period 2009-2011. We selected this cohort of patients because before diabetes onset they had not done any activity related to diabetes self-care included in the 15 questions of the SCI-R questionnaire, except exercise.
All patients were treated with multiple doses of insulin analogs and followed a specific, structured therapeutic education program during the first year, mixing individual and group interventions with the aim of providing patients and relatives with tailored competence for optimal self-care and diabetes control. The four steps of this program were: the initiation level made in the day center during the 3 days after diagnosis ( 3 hours per day and telephone consultation every night); basic level of therapeutic patient education group course lasting 4 days (half an hour each session) completed by each patient during the first 2 months after onset; individual follow-up over 12 months (4-6 appointments made in the diabetes outpatient clinic; and an advanced level therapeutic patient education course group lasting 5 days, with 2 hours at each session). During this process, patients can consult online information. ${ }^{24}$ A 24-hour emergency telephone contact is available. This program is targeted to people with new-onset type 1 diabetes. It was developed in 1990, with subsequent updates, the last being in 2009. It was devised by diabetes educator nurses and endocrinologists from the diabetes unit in the hospital clinic. One year after diabetes onset in each patient, we analyzed the following parameters:

- Sociodemographics, ie, age, gender, educational level

- Metabolic control, indicated by $\mathrm{HbA}_{1 \mathrm{c}}$ (National Glycohemoglobin Standardization Program [NGSP] Diabetes Control and Complication Trial [DCCT] TOSOH HLC-723 G8; Tosoh Bioscience, Kyoto, Japan: normal range NGPS $4.0 \%-6.0 \%$ or International Federation of Clinical Chemistry [IFCC] 20-42 $\mathrm{mmol} / \mathrm{mol}$ ); frequency of severe hypoglycemia events during the first year (events requiring treatment by a third party) and frequency of nonsevere hypoglycemia during the 2 weeks before evaluation (events defined as symptoms or signs associated with hypoglycemia experienced by the patient and self-treated without the need of assistance from a third party, or a blood glucose measurement $\leq 70 \mathrm{mg} / \mathrm{dL}[\leq 3.8 \mathrm{mmol} / \mathrm{mL}]$ )

- Awareness of hypoglycemia using the Clarke test ${ }^{25}$ consisting of eight questions, the answers to which could be classified as A (awareness) or R (reduced awareness); $>4 \mathrm{R}$ points presented unawareness of hypoglycemia

- Diabetes knowledge using the DKQ2 test ${ }^{26}$ consisting of 19 questions with multiple choice answers and a maximum score of 35

- Eating attitudes using the EAT26 test ${ }^{27}$ consisting of 26 questions each scored as 1, 2, or 3, with a total score $>20$ indicating an eating disturbance

- Quality of life perception using the Diabetes Quality of Life test ${ }^{28}$ that has four scales, ie, satisfaction 
(minimum score 15, maximum score 75), impact (minimum score 17 , maximum score 85 ), social worry (minimum score 7, maximum score 35 ), and diabetes worry (minimum score 4, maximum score 20), with a lower score indicating better perception

- SCI-R ${ }^{21}$ questionnaire, proposed to evaluate the responsiveness of change.

\section{Statistical analysis}

Descriptive statistics were used to describe demographic variables. Data are presented as the mean \pm standard deviation (SD) or the percentage. The Student's $t$-test was used for comparisons and the Pearson's coefficient for correlations. Cronbach's coefficient was used to assess the internal consistency of the SCI-R.

To examine the internal structure of the SCI-R, we performed exploratory principal component factor analysis, using orthogonal rotation (Varimax) to examine the pattern of loadings for evidence of a large general factor that would support use of a total score. A general factor would be evident if the first mean loading was high $(>0.30)$ and the standard deviation low for the first principal component and the mean low loadings and high SD for the remaining principal components. An item loading of $>0.40$ was the criterion of item salience of the rotated factor loadings used to guide interpretation.

The original survey ${ }^{21}$ scores were converted to a $0-100$ point scale for easier interpretation by subtracting the minimum possible item score from the individual's averaged raw score, multiplied by 100 . This value is then divided by the difference of the minimum possible item score subtracted from the maximum possible item score $([$ mean raw score - minimum $] \times 100) /$ (maximum - minimum). To determine the adherence of a specific group of patients, the data are expressed as the mean \pm SD. All statistical calculations were performed using Statistical Package for the Social Sciences version 19 software for personal computers (SPSS Inc., Chicago, IL, USA). The level of statistical significance was set at $P<0.05$.

\section{Results}

\section{Cultural adaptation and pilot scale understanding}

After translation from and translation back to English, ten words (Spanish version) and eight words (Catalan version) and verb tense in both questionnaires were modified for the unified Spanish and Catalan versions. Three words (Spanish version) and four words (Catalan version) were modified for the final Spanish and Catalan versions of the questionnaires (Table 1).

\section{Internal reliability, structural validity, and external validity \\ Validity}

A total of 195 patients in the four centers answered the final Spanish $(n=110)$ or Catalan $(n=85)$ versions; $64 \%$ of patients had type 1 diabetes, $46 \%$ were women, and the mean age was $36 \pm 18$ years. The level of education was: $25 \%$ primary, $30 \%$ secondary, and $35 \%$ university.

\section{Internal reliability}

Cronbach's alpha was 0.75 . Test-retest reliability showed $\mathrm{r}=0.82(P<0.001)$. Table 2 shows the mean and SD, the acceptability ( $\%$ floor and $\%$ ceiling), and the internal consistency reliability (item-total correlation and Cronbach's alpha if item deleted) for each item of the questionnaire.

\section{Structural validity}

Structural validity was $r=>0.40(P<0.001)$ on all questions except number 14 related to exercise $(P=0.09)$. Principal component analysis identified two main factors, ie, factor 1 (general) and factor 2 (related to regularity), as shown in Table 3 .

\section{External validity}

The correlation with $\mathrm{HbA}_{1 \mathrm{c}}$ in patients with type 1 diabetes was $r=-0.56(P<0.001)$ (multiple insulin doses $r=-0.50$ $[P<0.001]$; continuous subcutaneous insulin infusion $\mathrm{r}=-0.66[P<0.001])$ (Figure 1), being $\mathrm{r}=-0.13(P=0.30)$ (oral agents $\mathrm{r}=-0.20[P=0.24]$; bedtime insulin $\mathrm{r}=-0.35$ $[P=0.12]$; and multiple doses $\mathrm{r}=-0.62[P=0.001])$ in patients with type 2 diabetes. There were no differences in the self-care score according to age, diabetes duration, or education level, although statistical significance was observed in relation to type 1 diabetes versus type 2 diabetes $(69 \% \pm 12 \%$ versus $55 \% \pm 13 \%$, respectively, $P=0.01$ ).

\section{Responsiveness to change}

We evaluated 54 patients aged $27.3 \pm 7.4$ years $(26 \%$ men) 1 year after onset of type 1 diabetes. Twelve percent of the patients had no formal education, and $7 \%$ had primary, $28 \%$ had secondary, and $55 \%$ had university education. $\mathrm{HbA}_{1 \mathrm{c}}$ was $6.8 \% \pm 1.1 \%(51.6 \pm 12.2 \mathrm{mmol} / \mathrm{mol})$ compared with $11.9 \% \pm 3 \%(107 \pm 19 \mathrm{mmol} / \mathrm{mol})$ at onset $(P<0.001)$. The frequency of nonsevere hypoglycemic events was $1.5 \pm 2.06$ 
Table I Self-Care Inventory-Revised Version (SCI-R) Spanish version (SCI-R.es) ${ }^{\mathrm{a}}$ and Catalan version (SCl-R.cat) ${ }^{\mathrm{b}}$

This survey measures what you actually do, not what you are advised to do

Este cuestionario valora lo que usted hace actualmente (no lo que le han recomendado hacer) ${ }^{\mathrm{a}}$

Aquest qüestionari valora el que vosté fa actualment (no el que li han recomanat fer) ${ }^{b}$

How have you followed your diabetes treatment plan in the past I-2 months?

Cómo ha seguido el tratamiento de su diabetes en los últimos I-2 meses?a Cóm ha seguit el tractament de la seva diabetis en els darrers I-2 mesos? ${ }^{b}$

I. Check blood glucose with monitor

Mira la glucosa en sangre con el medidora

Mira la glucosa en sang amb el medidor ${ }^{b}$

2. Record blood glucose results

Registra los resultados de la glucosar ${ }^{a}$

Registra els resultats de la glucosa ${ }^{\mathrm{b}}$

3. If type I, check ketones when glucose levels are high

Si diabetes tipol: Mira la cetona si la glucosa es alta ${ }^{a}$

Si diabetis tipus I: Mira la cetona si la glucosa és alta ${ }^{b}$

4. Take the correct dose of diabetes pills or insulin

Toma la dosis indicada de pastillas o insulina ${ }^{a}$

Pren la dosi indicada de pastilles o insulina ${ }^{\mathrm{b}}$

5. Take diabetes pills or insulin at the right time

Toma las pastillas o insulina a las horas indicadas ${ }^{a}$

Pren les pastilles $o$ insulina a les hores indicades ${ }^{b}$

6. Eat the correct food portions

Toma las raciones de comida adecuadas ${ }^{a}$

Pren les racions de menjar adequades ${ }^{b}$

7. Eat meals/snacks on time

Toma las comidas o suplementos a su hora ${ }^{a}$

Pren els aptas o suplements a I'hora ${ }^{\mathrm{b}}$

8. Keep food records

Hace registro de los alimentos que toma ${ }^{a}$

Fa registres dels aliments que pren ${ }^{\mathrm{b}}$

9. Read food labels

Lee las etiquetas nutricionales de los alimentos ${ }^{\mathrm{a}}$

Llegeix les etiquetes nutricionals dels aliments ${ }^{\mathrm{b}}$

10. Treat low blood glucose with the recommended amount of carbohydrate

Trata la bajada de azúcar con la cantidad recomendada de hidratos de carbono ${ }^{a}$

Tracta la baixada de sucre amb la quantitat recomanada $d^{\prime} h i d r a t s ~ d e ~ c a r b o n i{ }^{b}$

I I. Carry rapid-acting sugar to treat low blood glucose

Lleva azúcar rápido para tratar una bajada de glucosa ${ }^{a}$

Porta sucre ràpid per a tractar una baixada de glucosa ${ }^{b}$

12. Come in for clinic appointments

Acude a las visitas médicas ${ }^{2}$

Acudeix a les visites médiques ${ }^{b}$

13. Wear a Medic Alert identification

Lleva carné de diabetes ${ }^{\mathrm{a}}$

Porta carnet de diabètic ${ }^{b}$

14. Exercise

Realiza ejercicio ${ }^{\mathrm{a}}$

Realitza exercici ${ }^{b}$

I5. If on insulin, adjust dosage based on glucose values, food, and exercise Si lleva insulina: Ajusta la dosis según los valores de glucosa, comida y ejercicioa

Si porta insulina: ajusta les dosis segons els valors de glucosa, menjar i exercici

\begin{tabular}{|c|c|c|c|c|}
\hline I & 2 & 3 & 4 & 5 \\
\hline I & 2 & 3 & 4 & 5 \\
\hline \multicolumn{5}{|c|}{ Have type 2 diabetes } \\
\hline \multicolumn{5}{|c|}{ Tengo diabetes tipo $2 .^{a}$ Tinc diabetis tipus 2.} \\
\hline I & 2 & 3 & 4 & 5 \\
\hline I & 2 & 3 & 4 & 5 \\
\hline I & 2 & 3 & 4 & 5 \\
\hline \multicolumn{5}{|c|}{ Not taking diabetes pills or insulin } \\
\hline \multicolumn{5}{|c|}{ No tomo ni pastillas ni insulina ${ }^{a}$} \\
\hline \multicolumn{5}{|c|}{ No prenc ni pastilles ni insulina ${ }^{b}$} \\
\hline I & 2 & 3 & 4 & 5 \\
\hline I & 2 & 3 & 4 & 5 \\
\hline 1 & 2 & 3 & 4 & 5 \\
\hline I & 2 & 3 & 4 & 5 \\
\hline I & 2 & 3 & 4 & 5 \\
\hline \multicolumn{5}{|c|}{ Never had low blood glucose } \\
\hline \multicolumn{5}{|c|}{ Nunca he tenido una bajada de glucosa ${ }^{a}$} \\
\hline \multicolumn{5}{|c|}{ Mai he tingut una baixada de glucosa ${ }^{b}$} \\
\hline I & 2 & 3 & 4 & 5 \\
\hline I & 2 & 3 & 4 & 5 \\
\hline 1 & 2 & 3 & 4 & 5 \\
\hline I & 2 & 3 & 4 & 5 \\
\hline I & 2 & 3 & 4 & 5 \\
\hline \multicolumn{5}{|c|}{ Not on insulin } \\
\hline \multicolumn{5}{|c|}{ No llevo insulina $a^{a}$} \\
\hline & to in & & & \\
\hline
\end{tabular}

Never Nunca. Mai. $^{b}$

Rarely Raramente. ${ }^{a}$ Quasi mai. ${ }^{b}$

Sometimes Algunas veces. ${ }^{a}$ Algunes vegades. ${ }^{b}$

Usually Casi siempre. ${ }^{a}$ Quasi sempre. ${ }^{b}$

Always Siempre. ${ }^{a}$ Sempre. ${ }^{b}$ 
Table 2 Mean (SD), acceptability (\% floor and \% ceiling), and internal consistency reliability for Diabetes Self-Care Inventory-Revised Version items

\begin{tabular}{|c|c|c|c|c|c|}
\hline \multirow[t]{2}{*}{ SCI-R items } & \multirow[t]{2}{*}{ Mean (SD) } & \multicolumn{2}{|c|}{ Acceptability } & \multicolumn{2}{|c|}{ Internal consistency reliability } \\
\hline & & $\%$ floor & \% ceiling & $\begin{array}{l}\text { Item-total } \\
\text { correlation }\end{array}$ & $\begin{array}{l}\text { Alpha if item } \\
\text { deleted }\end{array}$ \\
\hline I. Check blood glucose with monitor & $4.38(1.04)$ & 4.7 & 65.3 & 0.57 & 0.73 \\
\hline 2. Record blood glucose results & $3.60(1.45)$ & 14.7 & 40.0 & 0.40 & 0.74 \\
\hline 3. If type I, check ketones when glucose levels are high & $2.18(1.37)$ & 46.4 & 10.5 & 0.32 & 0.74 \\
\hline 4. Take the correct dose of diabetes pills or insulin & $4.75(0.59)$ & 1.1 & 80.4 & 0.32 & 0.74 \\
\hline 5. Take diabetes pills or insulin at the right time & $4.66(0.61)$ & 0.5 & 71.4 & 0.43 & 0.75 \\
\hline 6. Eat the correct food portions & $4.03(0.80)$ & 0.5 & 28.9 & 0.51 & 0.74 \\
\hline 7. Eat meals/snacks on time & $3.87(1.08)$ & 5.7 & 32.0 & 0.39 & 0.74 \\
\hline 8. Keep food records & $1.98(1.19)$ & 55.4 & 5.7 & 0.34 & 0.74 \\
\hline 9. Read food labels & $3.11(1.45)$ & 20.6 & 23.2 & 0.32 & 0.74 \\
\hline $\begin{array}{l}\text { 10. Treat low blood glucose with just the recommended } \\
\text { amount of carbohydrate }\end{array}$ & $3.98(1.08)$ & 3.4 & 37.3 & 0.54 & 0.73 \\
\hline II. Carry rapid-acting sugar to treat low blood glucose & $4.14(1.30)$ & 9.3 & 60.3 & 0.22 & 0.75 \\
\hline 12. Come in for clinic appointments & $4.78(0.61)$ & 1.0 & 84.9 & 0.40 & 0.74 \\
\hline 13. Wear a Medic Alert identification & $2.65(1.85)$ & 52.1 & 34.4 & 0.30 & 0.76 \\
\hline 14. Exercise & $3.45(1.16)$ & 6.7 & 22.2 & 0.11 & 0.76 \\
\hline $\begin{array}{l}\text { I5. If on insulin, adjust dosage based on glucose values, } \\
\text { food, and exercise }\end{array}$ & $4.32(1.10)$ & 4.7 & 62.7 & 0.40 & 0.74 \\
\hline
\end{tabular}

Notes: \% Floor is the percentage of patients who answered the minimum score (I); \% Ceiling is the percentage of patients who answered the maximum score (5). Values $>50 \%$ are shown in bold.

Abbreviations: SCI-R, Diabetes Self-Care Inventory-Revised Version; SD, standard deviation.

during the last 2 weeks before evaluation. One patient had one severe hypoglycemic event during this first year, and four patients had hypoglycemia unawareness (Clarke test $>4 \mathrm{R}$ points). Mean score on the Diabetes Knowledge DKQ2 test was $28.0 \pm 3.8$. No patient had eating disturbances

Table 3 Principal component analysis of the Spanish and Catalan versions of the Diabetes Self-Care Inventory-Revised Version

\begin{tabular}{lll}
\hline SCI-R items & Factor I & Factor 2 \\
\hline $\begin{array}{l}\text { - Item I } 0 \text { Treat low blood glucose with just } \\
\text { the recommended amount of carbohydrate }\end{array}$ & $\mathbf{0 . 7 4}$ & 0.17 \\
- Item I 5 If on insulin, adjust dosage based & $\mathbf{0 . 7 3}$ & $-\mathbf{0 . 4 5}$ \\
$\quad$ on glucose values, food, and exercise & & \\
- Item I Check blood glucose with monitor & $\mathbf{0 . 5 9}$ & $\mathbf{0 . 4 2}$ \\
- Item I 2 Come in for clinic appointments & $\mathbf{0 . 5 5}$ & 0.19 \\
- Item I $\mathbf{3}$ Wear a Medic Alert identification & $\mathbf{0 . 4 4}$ & 0.05 \\
- Item $\mathbf{3}$ If type I, check ketones when & $\mathbf{0 . 4 0}$ & 0.14 \\
glucose levels are high & & \\
- Item $\mathbf{9}$ Read food labels & 0.35 & 0.16 \\
- Item I I Carry rapid-acting sugar to treat & 0.29 & 0.10 \\
low blood glucose & & \\
- Item I 4 Exercise & 0.25 & -0.0 I \\
- Item $\mathbf{5}$ Take diabetes pills or insulin at the & 0.14 & $\mathbf{0 . 6 9}$ \\
right time & & \\
- Item $\mathbf{2}$ Record blood glucose results & 0.12 & $\mathbf{0 . 6 8}$ \\
- Item $\mathbf{6}$ Eat the correct food portions & 0.3 I & $\mathbf{0 . 6 7}$ \\
- Item $\mathbf{4}$ Take the correct dose of diabetes & 0.03 & $\mathbf{0 . 6 2}$ \\
- ills or insulin & & \\
- Item $\mathbf{7}$ Eat meals/snacks on time & 0.14 & $\mathbf{0 . 6 0}$ \\
\hline
\end{tabular}

Notes: Loadings following Varimax rotation. Loadings $\geq 0.40$ or $\leq-0.40$ are shown in bold.

Abbreviation: SCI-R, Diabetes Self-Care Inventory-Revised Version. (mean score $4.9 \pm 4.7$ ). Mean Diabetes Quality of Life scores were $29.8 \pm 9.8$ for satisfaction, $30.8 \pm 7.9$ for impact, $12.6 \pm 6.9$ for social worry, and $8.8 \pm 3.1$ for diabetes worry. The mean SCI-R was $72.3 \% \pm 13.7 \%$, and this value was negatively correlated with $\mathrm{HbA}_{1 \mathrm{c}}(\mathrm{r}=-0.42, P=0.02)$ and three scales of the Diabetes Quality of Life test (the lower the score, the better the perception), ie, impact ( $\mathrm{r}=-0.37$, $P=0.03)$, social worry $(\mathrm{r}=-0.36, P=0.03)$, and diabetes worry $(\mathrm{r}=-0.38, P=0.03)$. We did not observe any significant correlation between SCI-R score and age, gender, educational level, diabetes knowledge, and eating disturbances in this cohort of patients.

\section{Discussion}

This study analyzed the psychometric characteristics of the Spanish (SCI-R.es) and Catalan (SCI-R.cat) versions of the SCI-R and supported its cultural adaptation, reliability, and structural validity in both type 1 and type 2 diabetes. External validity was good in patients with type 1 diabetes treated with multiple insulin doses or continuous subcutaneous insulin infusion and in patients with type 2 diabetes and on multiple insulin doses, but was not satisfactory for patients taking oral agents or those on bedtime insulin, making further evaluation necessary.

We demonstrated good responsiveness to change in patients with type 1 diabetes 1 year after disease onset following a specific structured patient education program. 

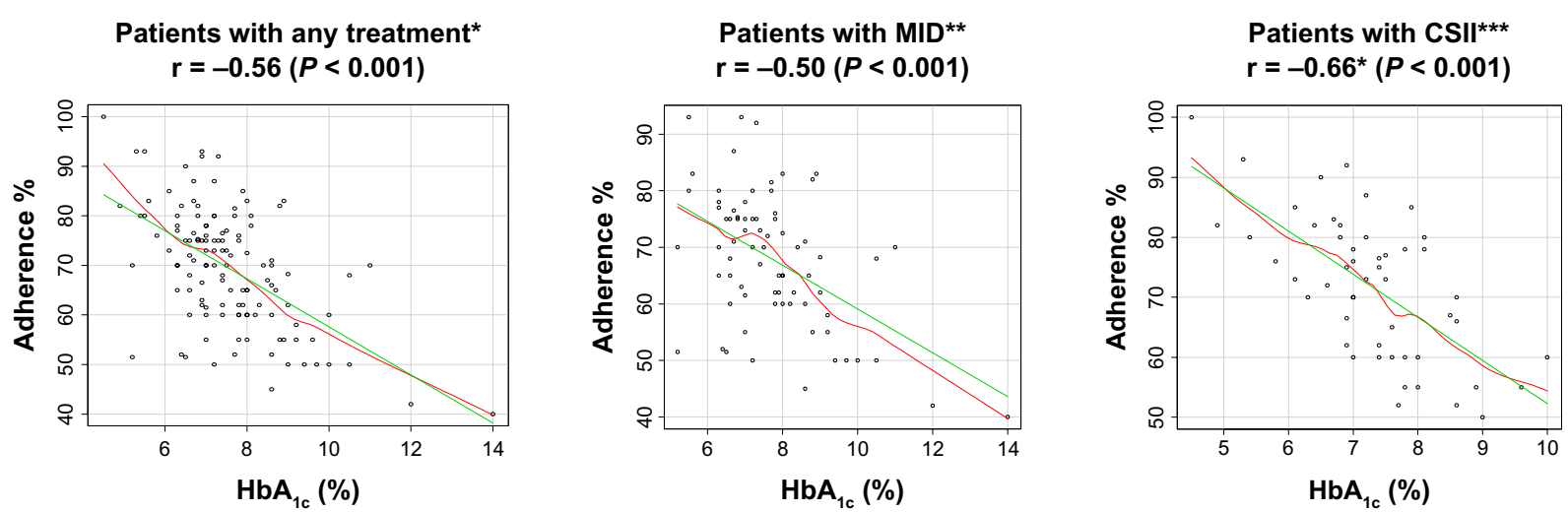

Figure I External correlation of Spanish and Catalan versions of Diabetes Self-Care Inventory-Revised Version with glycated hemoglobin in patients with type I diabetes. Notes: *patients with type I diabetes on any treatment; **patients with type I diabetes on multiple insulin doses; *** patients with type I diabetes on continuous subcutaneous insulin infusion. Adherence \%: mean SCl-R score.

Abbreviations: CSII, continuous subcutaneous insulin infusion; $\mathrm{HbA}_{\mathrm{Ic}}$, glycated hemoglobin; MID, multiple insulin doses; SCl-R, Self-Care Inventory-Revised Version.

These patients achieved high rates of adherence to self-care, and these rates correlated negatively with metabolic control (the higher the rate of self-care the lower the $\mathrm{HbA}_{1 \mathrm{c}}$ and the frequency of nonsevere hypoglycemia events) and also correlated negatively with three scales of quality of life perception, ie, impact, social worry, and diabetes worry (the higher the rates for self-care, the better the perception).

We have improved the psychometric validation of the SCI-R adapted by Weinger et $\mathrm{al}^{21}$ and proposed by Eigenmann et $\mathrm{a}^{23}$ because we included test-retest analysis. On the other hand, although the psychometric analysis of the original SCI-R in adults with diabetes had good external validity (correlation between total score and $\mathrm{HbA}_{1 c}$ ) in patients with type 1 or type 2 diabetes, it did not analyze different modalities of treatment. In our study, we evaluated the external correlation in type 1 diabetics on multiple insulin doses or continuous subcutaneous insulin infusion and type 2 diabetics on oral agents, bedtime insulin, or multiple insulin doses, demonstrating that this tool correlated well with $\mathrm{HbA}_{1 \mathrm{c}}$ in patients treated with multiple insulin doses or continuous subcutaneous insulin infusion.

In the recent psychometric validation of the SCI-R in the UK, Khagram et $\mathrm{al}^{22}$ demonstrated that the SCI-R is a brief, valid, and reliable measure of self-care in people with type 2 diabetes, but they did not assess test-retest reliability or responsiveness to change. Our psychometric analysis in patients with type 2 diabetes demonstrated good internal reliability (including Cronbach's alpha analysis and testretest reliability) and structural validity, although we did not demonstrate good external validity when correlating the global SCI-R score with $\mathrm{HbA}_{1 \mathrm{c}}$ in patients on oral agents or bedtime insulin, so future analysis is needed. This result may be associated with the items: "Check blood glucose with monitor?" and "Record blood glucose results?", given that the scores related to these questions varied greatly in patients with type 2 diabetes. One possible reason for this could be the economic policies of the Spanish and Catalan public health systems which, since 2011, have restricted payment for blood glucose strips in patients on oral agents and bedtime insulin. This issue should be analyzed in more depth. It is important to note that Khagram et a ${ }^{22}$ demonstrated that type 2 diabetes patients with $\mathrm{HbA}_{1 \mathrm{c}}<7.5 \%(<58 \mathrm{mmol} / \mathrm{mol})$ reported greater engagement in self-care behaviors when analyzed item by item and therefore recommended scoring of individual items as well as the total score on the SCI-R.

One limitation of our study and other measures of selfcare behavior is the lack of a "gold standard" comparison. Measuring treatment adherence presents difficulties because adherence is a personal behavior, so a patient may be adherent, nonadherent, or partially adherent with part or all of the treatment. It could be important for future studies to compare the Spanish and Catalan versions of the SCI-R with more objective measures of self-care behaviors. In a review by Garber et $\mathrm{al}^{29}$ on the concordance of self-report questionnaires, measures of medication adherence tended to have moderate-to-high concordance with other objective measures of medication adherence.

Another limitation of this study was the lack of a control group with which to compare the therapeutic patient education program. We did not include a control group for ethical reasons. There is strong evidence that patients with type 1 diabetes must optimize their metabolic control from the onset of the disease to prevent chronic complications of diabetes. At our center, the diabetes team made an update of this specific program in 2009.

According to Weinger et al, ${ }^{21}$ the SCI-R gives health care providers an indication of how well their patients follow self-care recommendations, but this information needs to be 
viewed in the context of a treatment program recommended for a particular patient. Another advantage reported by the same authors is that the SCI-R is short, taking only a few minutes for patients to complete, and is easily scored. Further, the individual items are useful for busy clinicians when starting a conversation about self-care behavior with their patients.

The different methods used to assess basic aspects of selfcare adherence are direct, indirect, and self-reported. The use of objective methods to evaluate adherence to medication, such as pill count, plasma drug concentration, and electronic monitors, can be costly in clinical practice. Self-report questionnaires are the easiest and most economic method, but may be subject to bias. It is important to take into account that patients may not answer what is correct but rather what they feel is right. Nonetheless, the use of specific and nonjudgmental questions, asked in a standard format, reduces this bias. Moreover, this questionnaire clearly states that it measures what patients actually do, not what they are advised to do.

The Australian consensus ${ }^{30}$ on outcomes and indicators for diabetes patient education supports the need for sound evidence on which diabetes education policy, programs, data collection, and research can be based. One area of work in this regard is developing tools which are psychometrically well validated.

\section{Conclusion}

The following conclusion can be made on the basis of the results of this study. The SCI-R.es and SCI-R.cat versions of the SCI-R are culturally well adapted and psychometrically sound measures of diabetes self-care behaviors in adults with type 1 or type 2 diabetes in terms of internal and structural validity. The external validity is good in type 1 diabetics on multiple insulin doses or continuous subcutaneous insulin infusion and in type 2 diabetics on multiple insulin doses. We were unable to demonstrate good external validity of the questionnaire in patients receiving oral agents or bedtime insulin, so further studies are needed. These questionnaires also demonstrate patient responsiveness to change 1 year after the onset of type 1 diabetes and following a specific structured patient education program. Use of well validated Spanish (SCI-R.es) and Catalan (SCI-R.cat) versions of the SCI-R questionnaire could help diabetes teams to perform the following easily in both clinical or research practice in Spain:

- Evaluation of the global degree of adherence to self-care and the individual degree of adherence to each component of patient self-care behaviors

- Detection of the behaviors showing greatest difficulty for further exploration of the psychosocial causes of poor adherence (eg, economic, depression, emotional) for patients at both the individual and group level

- Individualization of improvement strategies and particularly evaluation of the impact of patient education interventions in patients with type 1 diabetes at both the individual and group level.

\section{Acknowledgments}

We are grateful to Donna Pringle and Melisa Vance for their assistance with back translation of the questionnaires and to the patients who participated in this study. We also thank Professor Anne La Greca for permission to use the SCI-R questionnaire. This project was funded by the Catalan Association of Diabetes (therapeutic education grant 2008).

\section{Disclosure}

The authors report no conflicts of interest in this work.

\section{References}

1. American Diabetes Association. American Standards of Medical Care in Diabetes, 2012. Diabetes Care. 2012;35 Suppl 1:S11-S63.

2. Bosworth HB, Oddone EZ, Weinberger M. Medication treatment adherence. In: Bosworth Hayden Bye, Oddone Eugene Zgn, Weinberger Morris, editors. Patient Treatment Adherence. Concepts, Interventions and Measurements. London, UK: Lawrence Erlbaum Publishers; 2006.

3. American Association of Diabetes Educators. AADE7 Self-Care behaviors. Diabetes Educ. 2008;34:445-449.

4. World Health Organization. Adherence to long-term therapies: evidence for action. Available from: http://www.who.int/chp/knowledge/ publications/adherence_report/en/. Accessed August 12, 2013.

5. DiMatteo MR. Variations in patients' adherence to medical recommendations: a quantitative review of 50 years of research. Med Care. 2004;42:200-209.

6. Osterberg L, Blaschke T. Adherence to medication. $N$ Engl J Med. 2005;353:487-497.

7. Simpson SH, Eurich DT, Majumdar SR, et al. A meta-analysis of the association between adherence to drug therapy and mortality. $B M J$. 2006;333:15-18.

8. Jansà $\mathrm{M}$, Hernández $\mathrm{C}$, Vidal $\mathrm{M}$, et al. Multidimensional analysis of treatment adherence in patients with multiple chronic conditions. A cross-sectional study in a tertiary hospital. Patient Educ Couns. 2010;81:161-168.

9. van Dulmen S, Sluijs E, van Dijk L, de Ridder D, Heerdink R, Bensing J. Patient adherence to medical treatment: a review of reviews. BMC Health Serv Res. 2007;7:55.

10. Clifford S, Barber N, Horne R. Understanding different beliefs held by adherers, unintentional nonadherers, and intentional nonadherers: application of the Necessity-Concerns Framework. J Psychosom Res. 2008;64:41-46.

11. Odegard PS, Capoccia K. Medication taking and diabetes: a systematic review of the literature. Diabetes Educ. 2007;33:1014-1029.

12. González JS, Safren SA, Cagliero E, et al. Depression, self-care, and medication adherence in type 2 diabetes: relationships across the full range of symptom severity. Diabetes Care. 2007;30:2222-2227.

13. Currie CJ, Peyrot M, Morgan CL, et al. The impact of treatment noncompliance on mortality in people with type 1 diabetes. $J$ Diabetes Complications. 2013;27:219-223.

14. Ratanawongsa N, Karter AJ, Parker MM, et al. Communication and medication refill adherence: the diabetes study of northern California. JAMA Intern Med. 2013;173:210-218. 
15. Aikens JE, Piette JD. Longitudinal association between medication adherence and glycaemic control in type 2 diabetes. Diabet Med. 2013;30:338-344.

16. Peyrot M, Rubin RR, Lauritzen T, Snoek FJ, Matthews DR, Skovlund SE. Psychological problems and barriers to improved diabetes management results of the cross national diabetes, attitudes wishes and needs (DAWN) study. Diabet Med. 2005;22:1379-1385.

17. Gao J, Wang J, Zheng P, et al. Effects of self-care, self-efficacy, social support on glycemic control in adults with type 2 diabetes. BMC Fam Pract. 2013;24:14-66.

18. Beverly EA, Fitzgerald SM, Brooks KM, et al. Impact of reinforcement of diabetes self-care on poorly controlled diabetes: a randomized controlled trial. Diabetes Educ. 2013;39:504-514.

19. Shrivastava SR, Shrivastava PS, Ramasamy J. Role of self-care in management of diabetes mellitus. J Diabetes Metab Disord. 2013;12:14.

20. Golay A, Lagger G, Chambouleyron M, Carrard I, Lasserre-Moutet A. Therapeutic education of diabetic patients. Diabetes Metab Res Rev. 2008;24:192-196.

21. Weinger K, Butler HA, Welch GW, La Greca AM. A psychometric analysis of the Self-Care Inventory-Revised with adults. Diabetes Care. 2005;28:1346-1352.

22. Khagram L, Martin CR, Davies MJ, Speight J. Psychometric validation of the Self-Care Inventory-Revised (SCI-R) in UK adults with type 2 diabetes using data from the AT.LANTUS follow-on study. Health Qual Life Outcomes. 2013;11:24.
23. Eigenmann CA, Colagiuri R, Skinner TC, Trevena L. Are current psychometric tools suitable for measuring outcomes of diabetes education? Diabet Med. 2009;26:425-436.

24. Grau I, Grajales Iii FJ, Gene-Badia J, Siso A, de Semir M. Forumclinic: the shaping of virtual communities to assist patients with chronic diseases. Stud Health Technol Inform. 2013;183:271-275.

25. Clarke WL, Cox DJ, Gonder-Frederick LA, Julian D, Schlundt D, Polonsky W. Reduced awareness of hypoglycemia in adults with IDDM. A prospective study of hypoglycemic frequency and associated symptoms. Diabetes Care. 1995;18:517-522.

26. Lennon GM, Taylor KG, Debney L, Bailey CJ. Knowledge, attitudes, technical competence, and blood glucose control of type 1 diabetic patients during and after an education programme. Diabet Med. 1990;7:825-832.

27. Castro J, Toro J, Salamero M, Guimerá E. The Eating Attitudes Test: validation of the Spanish version. Psychol Assess. 1991;7: 175-190.

28. Millan M, Reviriego J, Del Campo J. Reappraisal of the Spanish version of the Diabetes Quality of Life Questionnaire. Endocrinol Nutr. 2002;49:322-324.

29. Garber MC, Nau DP, Erickson SR, Aikens JE, Lawrence JB. The concordance of self-report with other measures of medication adherence: a summary of the literature. Med Care. 2004;42:649-652.

30. Colagiuri R, Eigenmann CA. A national consensus on outcomes and indicators for diabetes patient education. Diabet Med. 2009;26: $442-446$.
Patient Preference and Adherence

\section{Publish your work in this journal}

Patient Preference and Adherence is an international, peer-reviewed, open access journal focusing on the growing importance of patient preference and adherence throughout the therapeutic continuum. Patient satisfaction, acceptability, quality of life, compliance, persistence and their role in developing new therapeutic modalities and compounds to

\section{Dovepress}

optimize clinical outcomes for existing disease states are major areas of interest. This journal has been accepted for indexing on PubMed Central. The manuscript management system is completely online and includes a very quick and fair peer-review system. Visit http://www.dovepress.com/ testimonials.php to read real quotes from published authors. 